\title{
Feline Experimental Organism Diagnosis
}

National Cancer Institute

\section{Source}

National Cancer Institute. Feline Experimental Organism Diagnosis. NCI Thesaurus. Code C134528.

A condition that is relevant to either disease states or models of disease in cats. 